\title{
Modulation of human platelet activation and in vivo vascular thrombosis by columbianadin: regulation by integrin $a_{1 \mathrm{lb}} \beta_{3}$ inside-out but not outside-in signals
}

Shaw-Min Hou ${ }^{1,2,3}$, Chih-Wei Hsia ${ }^{3}$, Cheng-Lin Tsai ${ }^{4}$, Chih-Hsuan Hsia ${ }^{3,5}$, Thanasekaran Jayakumar ${ }^{3}$, Marappan Velusamy ${ }^{6}$ and Joen-Rong Sheu ${ }^{3^{*}}$ (D)

\begin{abstract}
Background: Columbianadin (CBN) is one of the main coumarin constituents isolated from Angelica pubescens. The pharmacological value of CBN is well demonstrated, especially in the prevention of several cancers and analgesic activity. A striking therapeutic target for arterial thrombosis is inhibition of platelet activation because platelet activation significantly contributes to these diseases. The current study examined the influence of CBN on human platelet activation in vitro and vascular thrombotic formation in vivo.

Methods: Aggregometry, immunoblotting, immunoprecipitation, confocal microscopic analysis, fibrin clot retraction, and thrombogenic animals were used in this study.

Results: CBN markedly inhibited platelet aggregation in washed human platelets stimulated only by collagen, but was not effective in platelets stimulated by other agonists such as thrombin, arachidonic acid, and U46619. CBN evidently inhibited ATP release, intracellular $\left(\left[\mathrm{Ca}^{2+}\right] \mathrm{i}\right)$ mobilization, and P-selectin expression. It also inhibited the phosphorylation of phospholipase C (PLC)Y2, protein kinase C (PKC), Akt (protein kinase B), and mitogen-activated protein kinases (MAPKs; extracellular signal-regulated kinase [ERK] 1/2 and c-Jun N-terminal kinase [JNK] 1/2, but not p38 MAPK) in collagen-activated platelets. Neither SQ22536, an adenylate cyclase inhibitor, nor ODQ, a guanylate cyclase inhibitor, reversed the CBN-mediated inhibition of platelet aggregation. CBN had no significant effect in triggering vasodilator-stimulated phosphoprotein phosphorylation. Moreover, it markedly hindered integrin $a_{\| b} \beta_{3}$ activation by interfering with the binding of PAC-1; nevertheless, it had no influences on integrin $a_{\| 1} \beta_{3}$-mediated outside-in signaling such as adhesion number and spreading area of platelets on immobilized fibrinogen as well as thrombin-stimulated fibrin clot retraction. Additionally, CBN did not attenuate FITC-triflavin binding or phosphorylation of proteins, such as integrin $\beta_{3}$, Src, and focal adhesion kinase, in platelets spreading on immobilized fibrinogen. In experimental mice, CBN increased the occlusion time of thrombotic platelet plug formation.

Conclusion: This study demonstrated that CBN exhibits an exceptional activity against platelet activation through inhibition of the PLCY2-PKC cascade, subsequently suppressing the activation of Akt and ERKS/JNKs and influencing platelet aggregation. Consequently, this work provides solid evidence and considers that CBN has the potential to serve as a therapeutic agent for the treatment of thromboembolic disorders.
\end{abstract}

Keywords: CBN, Coumarin derivative, Platelet aggregation, Arterial thrombosis, Integrin $a_{\| b} \beta_{3}$

\footnotetext{
*Correspondence: sheujr@tmu.edu.tw

${ }^{3}$ Graduate Institute of Medical Sciences, College of Medicine, Taipei Medical

University, 250 Wu-Hsing Street, Taipei 110, Taiwan

Full list of author information is available at the end of the article
}

(c) The Author(s). 2020 Open Access This article is distributed under the terms of the Creative Commons Attribution 4.0 International License (http://creativecommons.org/licenses/by/4.0/), which permits unrestricted use, distribution, and reproduction in any medium, provided you give appropriate credit to the original author(s) and the source, provide a link to the Creative Commons license, and indicate if changes were made. The Creative Commons Public Domain Dedication waiver (http://creativecommons.org/publicdomain/zero/1.0/) applies to the data made available in this article, unless otherwise stated. 


\section{Introduction}

Arterial thrombosis can lead to the development of cardiovascular diseases (CVDs) such as myocardial infarction, atherosclerosis, and even ischemic stroke. When vascular subendothelial connective tissues are exposed due to injury, platelets move, adhere at the site of injury, and subsequently initiate the vascular thrombosis. Collagen contained in the basement membrane induces a change in shape from discoid to spheroid with pseudopodic projections of platelets. The combination of platelet secretion from the granules contain ADP/ATP, $\mathrm{Ca}^{2+}$, and fibrinogen, allows engagement of platelet receptors initiates intra-platelet signaling pathways, which activates platelet integrin $\alpha_{\mathrm{II}} \beta_{3}$ and enables platelet aggregation [1]. In resting platelets, integrin $\alpha_{\text {IIb }} \beta_{3}$ exists in a low activation state and is unable to interact with its specific ligands such as fibrinogen, fibronectin, and von Willebrand factor. Platelet activation stimulated by various agonists induces a conformational change in integrin $\alpha_{\mathrm{IIb}} \beta_{3}$, enabling it to bind to its ligands, resulting in the onset of platelet aggregation; this process is known as inside-out signal transduction [1]. Moreover, the binding of fibrinogen to activated integrin $\alpha_{\mathrm{IIb}} \beta_{3}$ initiates a series of intracellular signaling events, such as tyrosine phosphorylation of numerous proteins and cytoskeleton reorganization; this process is referred to as outside-in signaling [1]. These outside-in reactions, originating in the integrin $\alpha_{\mathrm{II}} \beta_{3}$ bound to fibrinogen, are required for maximal secretion, procoagulation, and clot retraction [1].

Columbianadin (CBN; Fig. 1a) is a natural coumarintype compound isolated from the root of Angelica pubescens Maxim. $f$. biserrata Shan et Yuan, which is mainly used to treat rheumatism, spasm, and headache in clinics, according to Chinese Pharmacopoeia [2]. Many coumarin derivatives are isolated from $A$. pubescens, of which CBN is one of the main bioactive constituents. $\mathrm{CBN}$ has attracted considerable attention due to its pharmacological properties, such as prevention of several types of cancers (i.e., human leukemia, bladder carcinoma, and colon cancer). It can effectively suppress the growth of colon cancer cells by inducing apoptosis at low concentrations $(\sim 25 \mu \mathrm{M})$ and necroptosis at high concentrations $(50 \mu \mathrm{M})$. The induction of apoptosis by $\mathrm{CBN}$ is correlated with the modulation of caspase-9, caspase-3, Bax, Bcl-2, $\mathrm{Bim}$, and Bid, and the induction of necroptosis is related to receptor-interacting protein kinase-3 and caspase-8 [2]. $\mathrm{CBN}$ also possesses analgesic properties. Moreover, it causes the inhibition of inflammatory responses, which markedly inhibited edema and the vascular permeability in mice and reduced the inflammatory response in LPSinduced lung injury through the downregulation of inducible nitric oxide synthase in mice [3, 4].

CBN was also preliminary reported to exhibit antiplatelet activity stimulated by ADP in rat platelets [5]; however, the effects and mechanisms of this compound on human platelets have not been investigated. Our initial screening exhibited that CBN significantly inhibits aggregation in human platelets. This result inspired us to conduct a thorough investigation on the influence of $\mathrm{CBN}$ on human platelets to support the scientific rationale for its clinical use (i.e., to treat CVDs).

\section{Materials and methods \\ Materials}

Collagen (type I), luciferin-luciferase, arachidonic acid (AA), U46619, ADP, fibrinogen, phorbol-12,13-dibutyrate $(\mathrm{PDBu})$, heparin, prostaglandin $\mathrm{E}_{1}\left(\mathrm{PGE}_{1}\right)$, fluorescein isothiocyanate (FITC)-phalloidin, nitroglycerin (NTG), aspirin and thrombin were purchased from Sigma (St. Louis, MO, USA). CBN (>98\%) was obtained from the ChemFaces Biohem (Wuhan, Hubei, China). Fura 2-AM was purchased from Molecular Probes (Eugene, OR, USA). The antiphospho-p38 mitogen-activated protein kinase (MAPK) Ser182, anti-integrin $\beta_{3}$ monoclonal antibodies (mAbs), and anti-phospho-integrin $\beta_{3}$ (Tyr759) polyclonal antibody (pAb) were purchased from Santa Cruz (Santa Cruz, CA, USA). The anti-p38 MAPK, anti-phospho-c-Jun N-terminal kinase (JNK) (Thr183/Tyr185), anti-phosphoSrc family (Tyr416), and anti-phospho-focal adhesion kinase (FAK) (Tyr397) mAbs and anti-phospholipase C (PLC) $\gamma 2$, anti-phospho (Tyr759) PLC 2 , anti-phospho-p44/ p42 extracellular signal-regulated kinase (ERK) (Thr202/ Tyr204), and anti-Src family pAbs were purchased from Cell Signaling (Beverly, MA, USA). The anti-phosphoprotein kinase B (Akt; Ser473) and anti-Akt mAbs were purchased from Biovision (Mountain View, CA, USA). An anti-FAK pAb was obtained from Millipore (Billerica, MA, USA). The anti- $\alpha$-tubulin $\mathrm{mAb}$ was purchased from NeoMarkers (Fremont, CA, USA). FITC-anti-human CD42P (P-selectin) and FITC-anti-human CD41/CD61 (PAC-1) mAbs were obtained from BioLegend (San Diego, CA, USA). Protein G Mag Sepharose Xtra Beads were purchased from GE Healthcare (Uppsala, Sweden). A Hybond-P Polyvinylidene difluoride membrane, an enhanced chemiluminescence Western blotting detection reagent, horseradish peroxidase-conjugated donkey anti-rabbit immunoglobulin G (IgG), and sheep antimouse IgG were purchased from Amersham (Buckinghamshire, UK). CBN suspension was prepared in $0.1 \%$ dimethyl sulfoxide (DMSO) and stored at $4{ }^{\circ} \mathrm{C}$.

\section{Platelet preparation, aggregation, and ATP release}

This study complied with the directives of the Helsinki Declaration and was approved by the Institutional Review Board of Taipei Medical University. Informed consent was obtained from all human volunteers who participated in this study. Washed human platelets $\left(3.6 \times 10^{8}\right.$ cells $\left./ \mathrm{mL}\right)$ were prepared as described previously [6], and CBN 


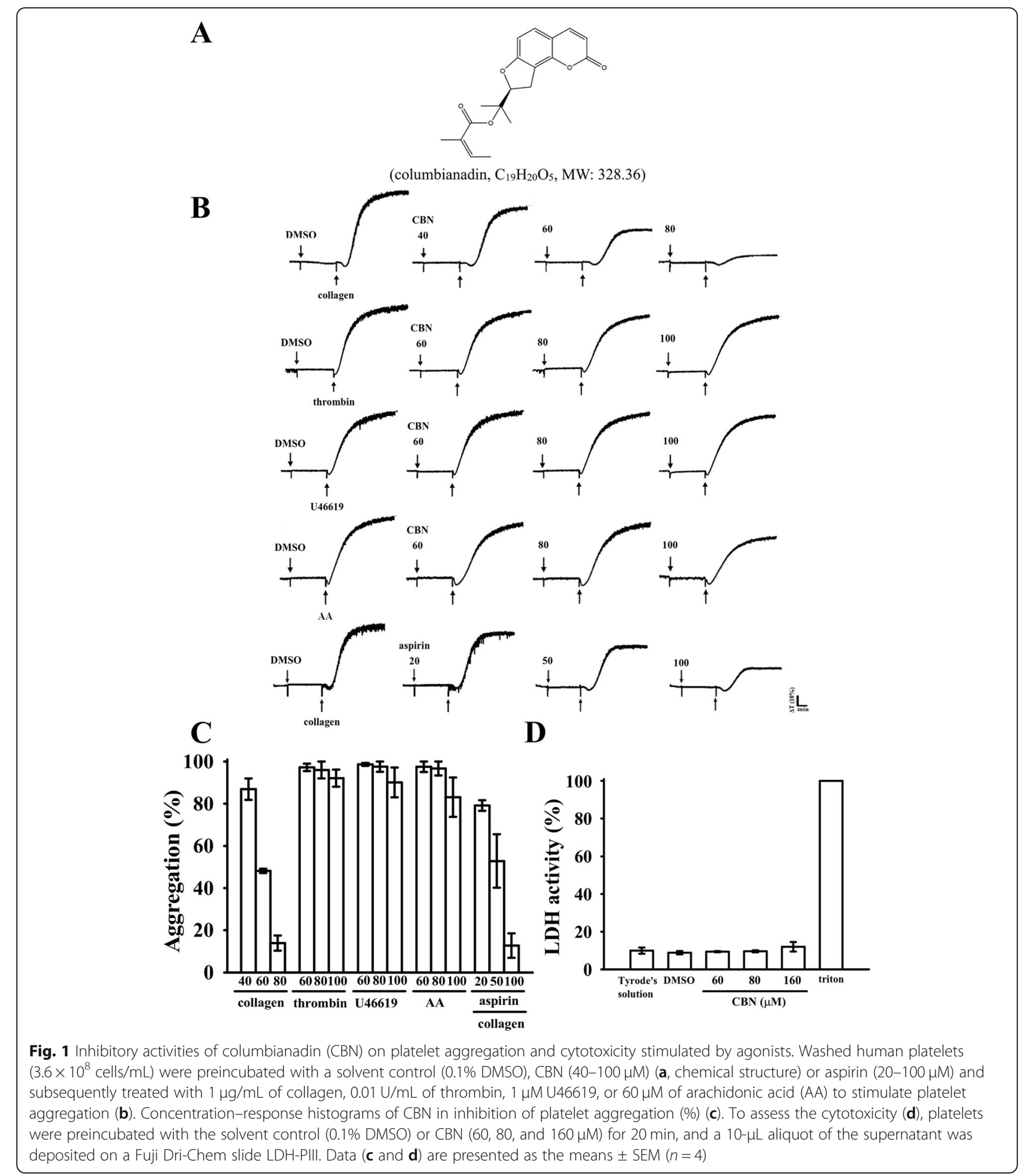

$(10-100 \mu \mathrm{M})$, aspirin $(20-100 \mu \mathrm{M})$ or solvent control (0.1\% DMSO) was incubated with the platelets for 3 min before stimulation. ATP release was measured using Hitachi Spectrometer F-7000 (Tokyo, Japan) according to the manufacturer's protocol.
Intracellular $\left[\mathrm{Ca}^{2+}\right] \mathrm{i}$ mobilization and lactate dehydrogenase assays

To measure the intracellular calcium $\left[\mathrm{Ca}^{2+}\right] \mathrm{i}$, citrated whole blood was centrifuged, and the supernatant was incubated with $5 \mu \mathrm{M}$ Fura 2-AM, which was then 
measured using a Hitachi Spectrometer F-7000 (Tokyo, Japan). $\left[\mathrm{Ca}^{2+}\right] \mathrm{i}$ was measured at excitation wavelengths of 340 and $380 \mathrm{~nm}$ and an emission wavelength of 500 nm [7]. Furthermore, cytotoxic effect was examined by determining the level of lactate dehydrogenase (LDH). Washed platelets were preincubated with $\mathrm{CBN}(60,80$, and $160 \mu \mathrm{M}$ ) or $0.1 \%$ DMSO for $20 \mathrm{~min}$ at $37^{\circ} \mathrm{C}$. An aliquot of the supernatant $(10 \mu \mathrm{L})$ was deposited on a Fuji Dri-Chem slide LDH-PIII (Fuji, Tokyo, Japan), and the absorbance was read using a spectrophotometer (UV160; Shimadzu, Japan). The maximal value of LDH was observed in triton-treated platelets.

\section{Surface P-selectin expression and integrin $\alpha_{11 b} \beta_{3}$ activation}

Briefly, washed platelets were preincubated with CBN (60 and $80 \mu \mathrm{M})$ and the FITC-conjugated anti-P-selectin mAb $(2 \mu \mathrm{g} / \mathrm{mL})$ or PAC- $1 \mathrm{mAb}(2 \mu \mathrm{g} / \mathrm{mL})$ for $3 \mathrm{~min}$ and then stimulated by collagen $(1 \mu \mathrm{g} / \mathrm{mL})$. For other experiments, fluorescence-conjugated triflavin, a specific integrin $\alpha_{\text {III }} \beta_{3}$ antagonist, was prepared as described previously [8]. The final concentration of FITC-triflavin was adjusted to $1 \mathrm{mg} / \mathrm{mL}$. Washed platelets were preincubated with EDTA $(2 \mathrm{mM}), \mathrm{CBN}(60$ and $80 \mu \mathrm{M})$ or solvent control (0.1\% DMSO), followed by the addition of FITCtriflavin $(2 \mu \mathrm{g} / \mathrm{mL})$ for $3 \mathrm{~min}$. The suspensions were then assayed for fluorescein-labeled platelets on a flow cytometer (FAC Scan system, Becton Dickinson, San Jose, CA, USA). Data were collected from 50,000 platelets per experimental group, and the platelets were identified based on their characteristic forward and orthogonal light-scattering profiles. All experiments were repeated at least four times to ensure reproducibility.

\section{Confocal microscopic analysis of platelet adhesion and spreading on immobilized fibrinogen}

Platelet spreading on immobilized fibrinogen was analyzed as described previously [9]. In brief, platelets were stained with FITC-labeled phalloidin and visualized with a Leica TCS SP5 microscope equipped with a 100×, 1.40 NA oil immersion objective (Leica, Wetzlar, Germany). The number of platelet adhesion events and the platelet spreading surface area were determined using the NIH ImageJ software (NIH, Bethesda, MD; http://rsbweb.nih.gov/ij/).

\section{Platelet-mediated fibrin clot retraction}

Washed platelets were suspended in Tyrode's solution containing $2 \mathrm{mg} / \mathrm{mL}$ fibrinogen and $1 \mathrm{mM} \mathrm{CaCl}_{2}$ in tubes designed for aggregation [10]. The platelet suspensions were preincubated in CBN $(60$ and $80 \mu \mathrm{M})$ or $0.1 \%$ DMSO for $3 \mathrm{~min}$ prior to thrombin $(0.01 \mathrm{U} / \mathrm{mL})$-induced clot retraction without stirring. The reaction was photographed at 15 and $30 \mathrm{~min}$, respectively.

\section{Immunoblotting}

Washed platelets $\left(1.2 \times 10^{9}\right.$ cells $\left./ \mathrm{mL}\right)$ were preincubated with CBN $(60$ and $80 \mu \mathrm{M})$ or $0.1 \%$ DMSO, and collagen was subsequently added to trigger activation. The platelet suspensions were lysed and separated on a $12 \%$ SDS-PAGE. Several proteins were detected by specific primary antibodies. Respective quantitative results were obtained by quantifying the optical density of protein bands using a video densitometer and Bio-profil Biolight software, Version V2000.01 (VilberLourmat, Marne-la-Vallée, France).

\section{Immunoprecipitation}

Dishes (6-cm diameter) were precoated with fibrinogen $(100 \mu \mathrm{g} / \mathrm{mL})$ overnight and then blocked with $1 \%$ BSA. Washed platelets were preincubated with CBN $(80 \mu \mathrm{M})$ or the solvent control (0.1\% DMSO) for $3 \mathrm{~min}$ and then allowed to spread on dishes for $60 \mathrm{~min}$. The platelets were lysed and centrifuged; subsequently, Protein G Mag Sepharose Xtra beads $(10 \mu \mathrm{L})$ was added and the platelets were incubated with the anti-integrin $\beta_{3} \mathrm{mAb}$ $(1 \mu \mathrm{g} / \mathrm{mL})$ for immunoblotting as described previously.

\section{Vascular thrombus formation in mouse mesenteric microvessels irradiated by sodium fluorescein}

The method applied to the thrombogenic animal model in this experiment conformed to the Guide for the Care and Use of Laboratory Animals (8th edition, 2011), and we received an affidavit of approval for the animal use protocol from Taipei Medical University. In brief, external jugular veins of mice ( 6 weeks old) were cannulated with a polyethylene (PE)-10 tube for administration of the sodium fluorescein $(15 \mu \mathrm{g} / \mathrm{kg})$ and CBN (5 and $10 \mathrm{mg} / \mathrm{kg}$ ) intravenously as described previously [11]. Venules (30$40 \mu \mathrm{m}$ ) were irradiated with wavelengths of $<520 \mathrm{~nm}$ to produce a microthrombus, and the time required for the thrombus to occlude the microvessel (occlusion time) was recorded.

ADP-induced acute pulmonary thromboembolism in mice Acute pulmonary thromboembolism was induced according to a previously described method [12]. Various doses of CBN (5 and $10 \mathrm{mg} / \mathrm{kg}$ ), aspirin $(20 \mathrm{mg} / \mathrm{kg}$ ) or solvent control (0.1\% DMSO) (all in $50 \mu \mathrm{L}$ ) were administered through intraperitoneal injection to mice. After $5 \mathrm{~min}$, ADP $(0.7 \mathrm{mg} / \mathrm{g})$ was injected into the tail vein. The mortality of mice in each group within $10 \mathrm{~min}$ after injection was determined.

\section{Statistical analysis}

The results are expressed as the means \pm SEM and are accompanied by the number of observations $(n) . n$ refers to the number of experiments, and each experiment was conducted using different blood donors. The unpaired 
Student's $t$ test or analysis of variance was used to determine the significant differences among the groups. When this analysis indicated significant differences, the groups were compared using the Student-NewmanKeuls method. Statistical significance was set at $p<0.05$.

\section{Results \\ Inhibitory activities of CBN in platelet aggregation stimulated by various agonists}

CBN (M.W. 328.36; $\mathrm{C}_{19} \mathrm{H}_{20} \mathrm{O}_{5}$ ) is a coumarin derivative of (Z)-2-methyl-2-butenoic acid 2-[(8S)-2-oxo-8, 9-dihydrofuro[2,3-h] [1] benzopyran-8-yl]propan-2-yl ester (Fig. 1a). Li et al. [5] reported that CBN significantly inhibits rat platelet aggregation stimulated by ADP. However, no other study has reported this effect of CBN. In the current study, CBN (40-80 $\mu \mathrm{M})$ more selectively inhibited human platelet aggregation stimulated by collagen $(1 \mu \mathrm{g} / \mathrm{mL})$ than $\mathrm{AA}$, thrombin, or U46619 (a thromboxane $\mathrm{A}_{2}$ receptor agonist). Although CBN slightly but no significantly inhibited platelet aggregations even at concentrations up to $100 \mu \mathrm{M}$ (Fig. $1 \mathrm{~b}-\mathrm{c})$. The $50 \%$ inhibitory concentration $\left(\mathrm{IC}_{50}\right)$ of $\mathrm{CBN}$ for collagen-induced platelet aggregation was approximated at $60 \mu \mathrm{M}$ (Fig. 1c). Moreover, aspirin (20, 50, and $100 \mu \mathrm{M})$ concentration-dependently inhibited platelet aggregation stimulated by collagen $(1 \mu \mathrm{g} / \mathrm{mL})$, and its $\mathrm{IC}_{50}$ value was approximated at $70 \mu \mathrm{M}$ (Fig. 1b and c). The solvent control (0.1\% DMSO) did not exert any significant effects on platelet aggregation (Fig. 1b). The LDH study revealed that $\mathrm{CBN}(60,80$, and $160 \mu \mathrm{M})$ did not alter LDH release or have any cytotoxic effects on platelets (Fig. 1d). This result revealed that CBN did not affect platelet permeability or induce platelet cytolysis.

\section{Regulatory profiles of CBN in ATP release, $\left[\mathrm{Ca}^{2+}\right]$ mobilization, and P-selectin expression}

Platelet activation is associated with the release of granular contents (e.g., P-selectin from $\alpha$-granules, ADP/ATP and $\mathrm{Ca}^{2+}$ from dense granules), causing amplification of platelet activation. P-selectin is located on the inner wall of $\alpha$-granules in the resting platelets, and the inner walls of the granules are exposed on the outside of the cells after activation [13]. CBN evidently reduced collagenstimulated surface P-selectin expression (resting control, $67.0 \pm 11.1$; collagen-activated, $531.3 \pm 59.3$; CBN $60 \mu \mathrm{M}$, $277.0 \pm 44.6$; and CBN $80 \mu \mathrm{M}, 195.3 \pm 28.4$; $n=4$; Fig. $2 \mathrm{a}$ ). As presented in Fig. 2b, CBN diminished the ATPrelease reaction stimulated by collagen $(1 \mu \mathrm{g} / \mathrm{mL})$, but not by AA $(60 \mu \mathrm{M})$. Moreover, collagen triggered a relative increase in $\left[\mathrm{Ca}^{2+}\right] \mathrm{i}$, which was markedly reduced in the presence of $\mathrm{CBN}(60$ and $80 \mu \mathrm{M})$ approximately by 40 and $70 \%$, respectively (Fig. 2 c).

\section{Effectiveness of CBN in PLC 2 /protein kinase $C$ (PKC) and Akt activation}

PLC, belonging to a family of kinases, hydrolyzes phosphatidylinositol 4,5-bisphosphate $[\mathrm{PI}(4,5) \mathrm{P} 2]$ to produce two important secondary messengers, diacylglycerol (DAG) and inositol trisphosphate $\left(\mathrm{IP}_{3}\right)$. DAG activates the PKC-inducing pleckstrin phosphorylation $(47 \mathrm{kD}$ protein) and ATP release in activated platelets; $\mathrm{IP}_{3}$ elevates calcium influx [14]. CBN (60 and $80 \mu \mathrm{M})$ obviously diminished the PLC $\gamma 2$ phosphorylation and PKC activation in collagen-activated platelets (Figs. $3 \mathrm{a}-\mathrm{b}$ ). CBN did not significantly reduce $\mathrm{PDBu}$ (PKC activator)-induced platelet aggregation at 60 or $80 \mu \mathrm{M}$ (Fig. 3c), indicating that $\mathrm{CBN}$ did not directly influence PKC activation. In addition, the Akt (Ser-Thr kinase) pathway or termed PI3K (phosphatidylinositol 3-kinase)-Akt pathway mediates downstream responses, including cell survival, growth, and platelet activation [15]. CBN (60-100 $\mu \mathrm{M})$ markedly diminished the phosphorylation of Akt stimulated by collagen, but not by AA (Fig. 3d).

\section{Regulatory activities of CBN in MAPK activation}

The inhibitory mechanisms of $\mathrm{CBN}$ in platelet activation were examined by investigating several MAPK signals, such as ERK1/2, JNK1/2, and p38 MAPK, which control major cellular functions, including proliferation, differentiation, and platelet activation [16]. Interestingly, CBN inhibited the phosphorylation of either ERK1/2 (Fig. 4a) or JNK1/2 (Fig. 4b), but not p38 MAPK (Fig. 4c), indicating that inhibition of the ERK1/2 and JNK1/2 signaling may be crucially involved in CBN-mediated inhibitory mechanisms.

\section{Roles of CBN in intracellular cyclic nucleotide formation and integrin $\alpha_{11 b} \beta_{3}$ activation}

Cyclic nucleotides such as cyclic AMP and cyclic GMP are critical secondary messengers that regulate multiple targets including different protein kinases, which have been reported to be involved in the phosphorylation of vasodilator-stimulated phosphoprotein (VASP). As illustrated in Fig. 5a, both ODQ $(10 \mu \mathrm{M})$, a guanylate cyclase inhibitor and SQ22536 $(100 \mu \mathrm{M})$, an adenylate cyclase inhibitor, significantly reversed NTG $(10 \mu \mathrm{M})$ - and PGE $_{1}$ $(1 \mu \mathrm{M})$-mediated inhibition of collagen-induced platelet aggregation, respectively. Neither ODQ nor SQ22536 significantly reversed $\mathrm{CBN}(80 \mu \mathrm{M})$-mediated inhibition of platelet aggregation. Furthermore, both NTG $(10 \mu \mathrm{M})$ and $\mathrm{PGE}_{1}(1 \mu \mathrm{M})$ obviously stimulated VASP phosphorylation, whereas CBN (60 and $80 \mu \mathrm{M})$ had no effects on cyclic nucleotide formation. Platelet aggregation is dependent on fibrinogen-integrin $\alpha_{\text {IIb }} \beta_{3}$ interaction; nevertheless, integrin $\alpha_{\text {IIb }} \beta_{3}$ inactivation can lead to disaggregation of aggregated platelets [17]. To further define whether $\mathrm{CBN}$ could disturb integrin $\alpha_{\mathrm{IIb}} \beta_{3}$ activation, the binding of the FITCconjugated PAC-1 mAb that reacts with activation-induced 
A

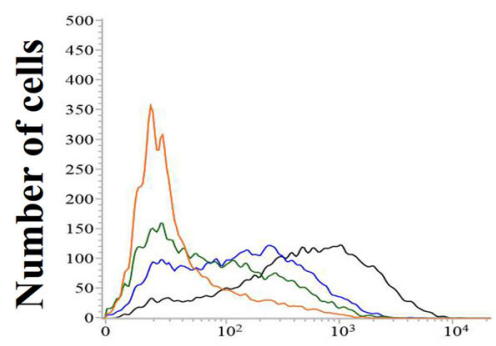

Fluorescence intensity

B
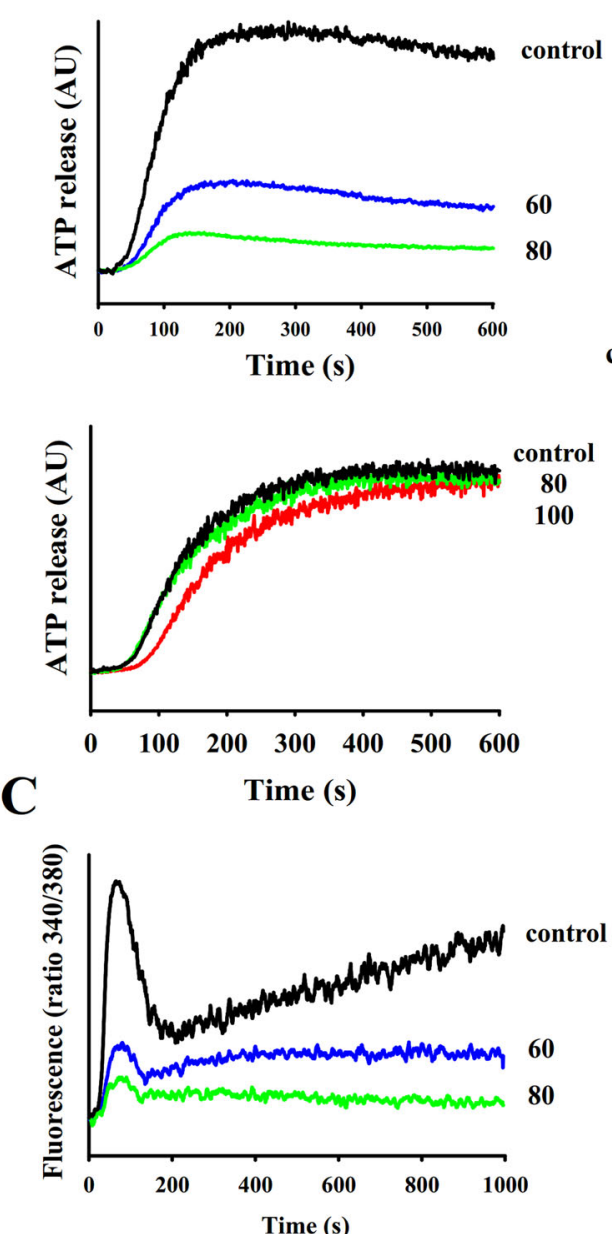
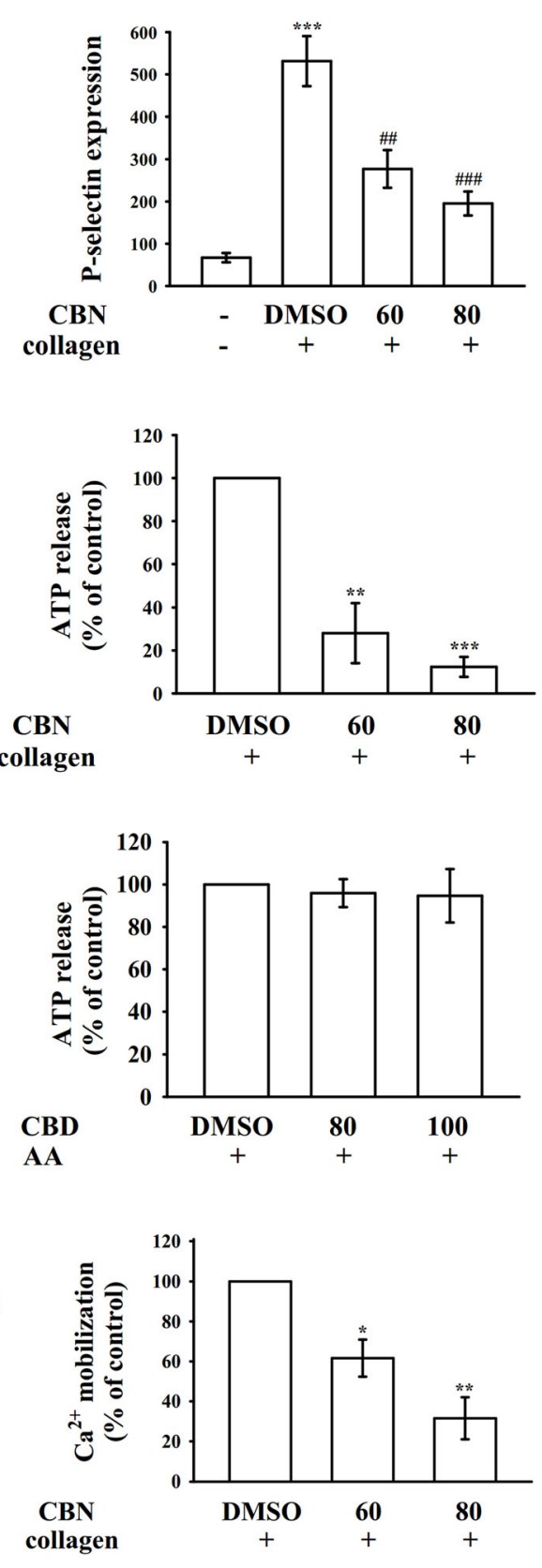

Fig. 2 Effectiveness of columbianadin (CBN) on surface P-selectin expression, ATP releases, and relative $\left[\mathrm{Ca}^{2+}\right] \mathrm{i}$ mobilization in human platelets. Washed platelets $\left(3.6 \times 10^{8}\right.$ cells $\left./ \mathrm{mL}\right)$ were preincubated with the solvent control $(0.1 \%$ DMSO) or CBN $(60$ and $80 \mu \mathrm{M})$, followed by the addition of collagen $(1 \mu \mathrm{g} / \mathrm{mL})$ or arachidonic acid $(\mathrm{AA} ; 60 \mu \mathrm{M})$ to trigger (a) surface P-selectin expression (resting control, red line; collagen-activated, black line; CBN $60 \mu \mathrm{M}$, blue line; CBN $80 \mu \mathrm{M}$, green line), (b) ATP release (AU; arbitrary unit), and (c) relative [Ca ${ }^{2+}$ ]i mobilization, as described in the Materials and methods section. The corresponding statistical data are presented in the right panel of each figure. Data are presented as means \pm SEM $(n=4) .{ }^{*} p<0.05,{ }^{* *} p<0.01$, and ${ }^{* * *} p<0.001$ compared with the resting control; ${ }^{\# \#} p<0.01$ and ${ }^{\# \# \#} p<0.001$, compared with the $0.1 \%$ DMSO-treated group

conformational epitope of the integrin $\alpha_{\mathrm{II}} \beta_{3}$ was analyzed through flow cytometry. CBN treatment $(60$ and $80 \mu \mathrm{M})$ considerably affected integrin $\alpha_{\mathrm{II}} \beta_{3}$ activation stimulated by collagen, indicating that $\mathrm{CBN}$ may be interrupting the binding of activated integrin $\alpha_{\mathrm{IIb}} \beta_{3}$ (Fig. 5c). Furthermore, platelets adhered immobilized fibrinogen more significantly than immobilized bovine serum albumin (BSA) (Fig. 6a $a-b$ ), which was revealed by staining platelets with FITC-conjugated phalloidin. No significant differences were observed in platelet adhesion and spreading on 
A

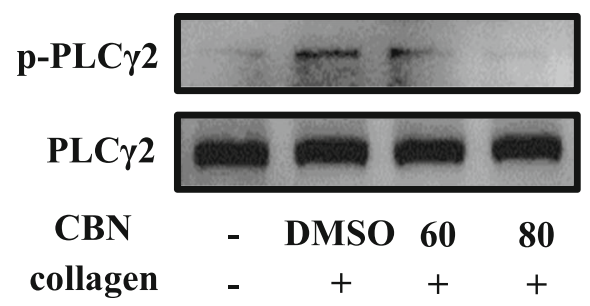

B

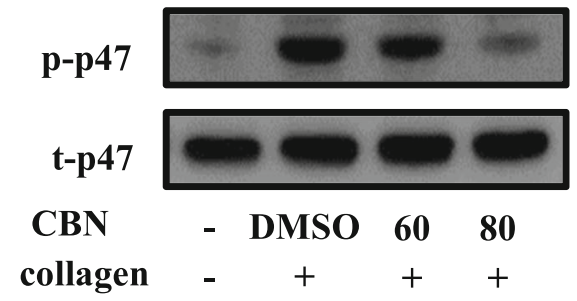

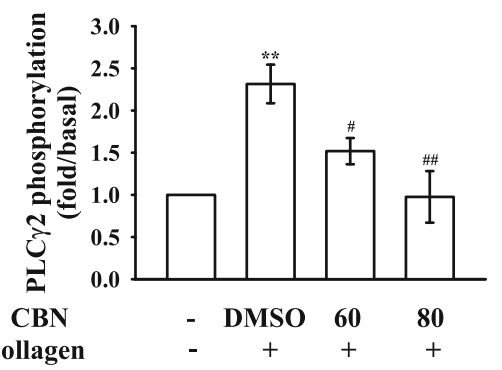

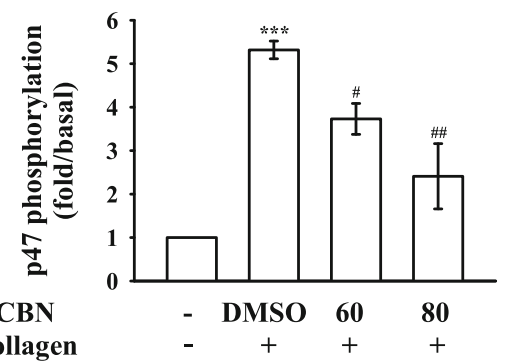

C
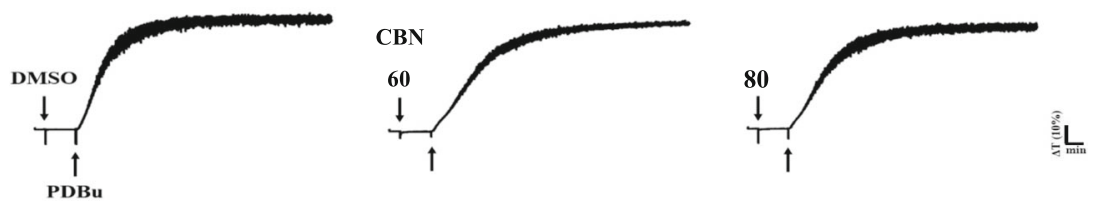

D
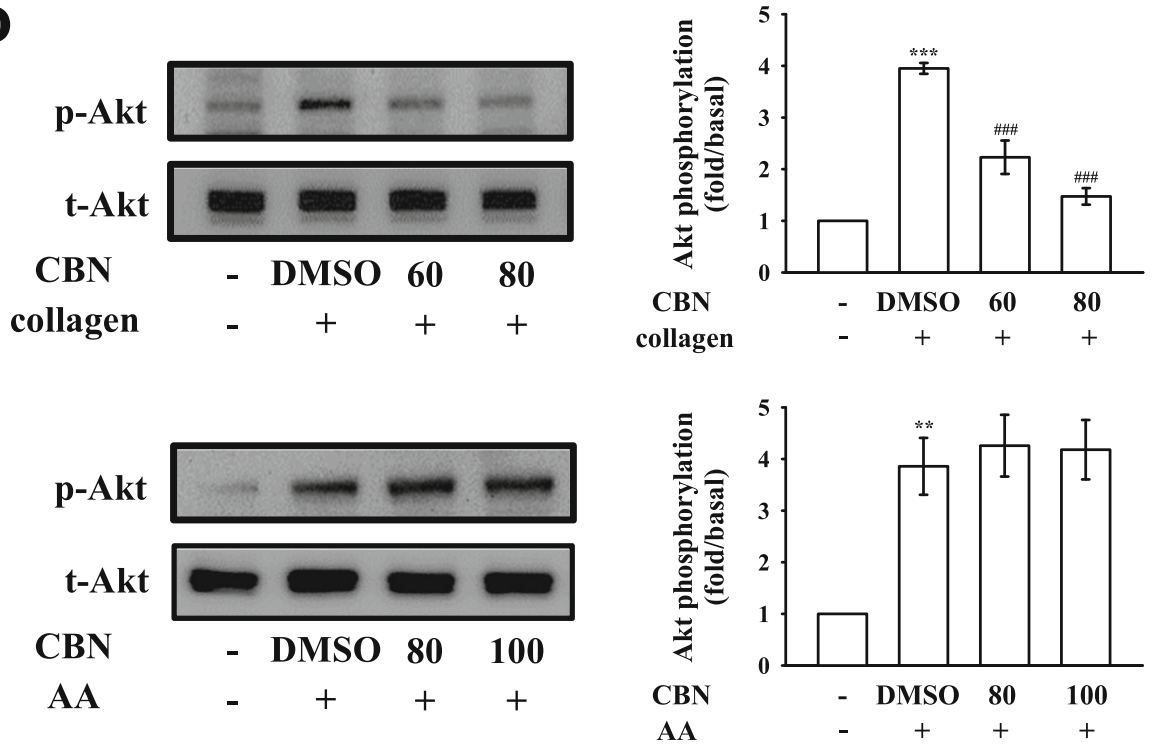

Fig. 3 Regulatory effects of columbianadin (CBN) on PLCY2/PKC and Akt phosphorylation in platelets. Washed platelets were preincubated with a solvent control (0.1\% DMSO) or CBN (60 and $80 \mu \mathrm{M})$ and subsequently treated with collagen $(1 \mu \mathrm{g} / \mathrm{mL})$, PDBu (150 nM) or arachidonic acid (AA; $60 \mu \mathrm{M}$ ) to trigger either (a) PLCY2, (b) PKC (p47) activation or (c) platelet aggregation, and (d) Akt phosphorylation. Profiles in (c) are

representative of four independent experiments. Data are presented as the means \pm SEM $(n=4) .{ }^{* *} p<0.01$ and ${ }^{* * *} p<0.001$, compared with the

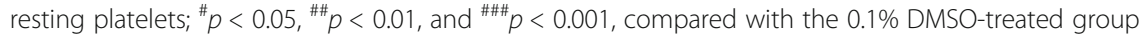

immobilized fibrinogen for the CBN (60 and $80 \mu \mathrm{M})$ treated platelets compared with the 0.1\% DMSOtreated platelets (Fig. 6a $c-d$ ). As illustrated in Fig. 6b, control platelets were more predominantly fixed to immobilized fibrinogen compared with immobilized
BSA (BSA, $29.7 \pm 3.8$ platelets $/ 0.01 \mathrm{~mm}^{2}$ and fibrinogen, $104.3 \pm 16.2$ platelets $\left./ 0.01 \mathrm{~mm}^{2} ; n=4\right)$; however, both 60 and $80 \mu \mathrm{M}$ CBN-treated platelets had similar adhesion to the fibrinogen-coated surface $(60 \mu \mathrm{M}, 90.3 \pm$ 19.3 platelets $/ 0.01 \mathrm{~mm}^{2}, \quad n=4$ and $80 \mu \mathrm{M}, 92.7 \pm 7.4$ 
A

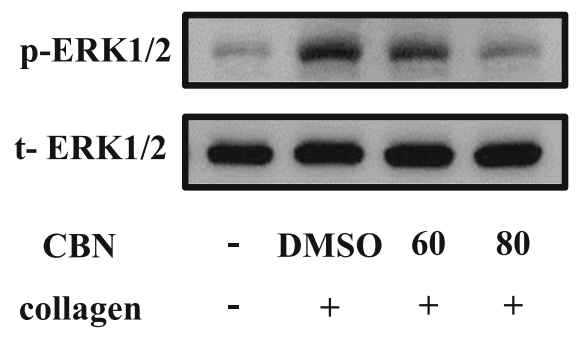

B
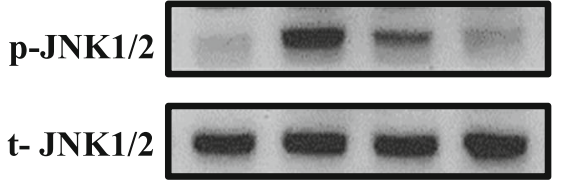

CBN collagen

- DMSO $60 \quad 80$
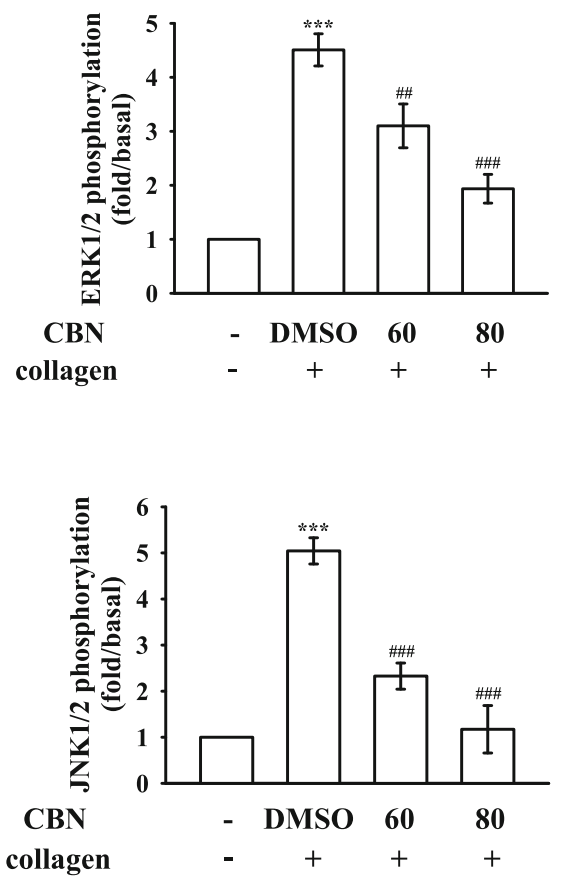

C
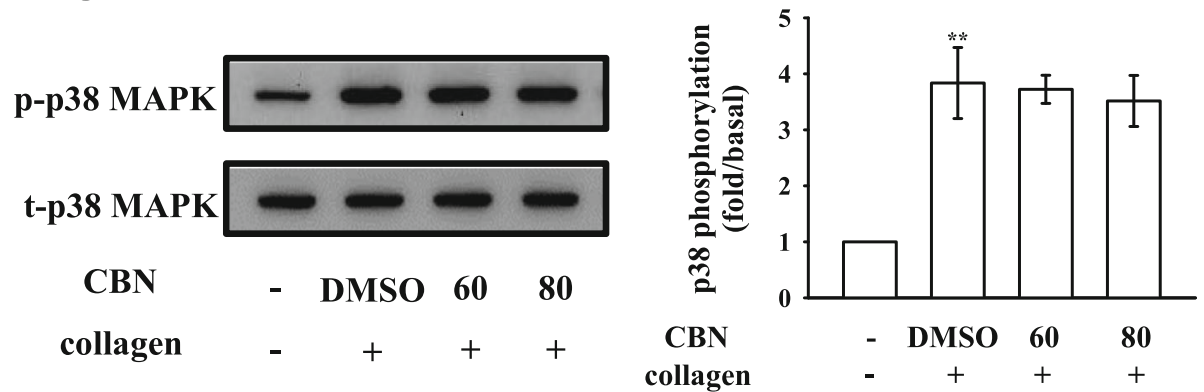

Fig. 4 Effect of columbianadin (CBN) on ERK1/2, JNK1/2, and p38 MAPK phosphorylation in collagen-activated platelets. Washed platelets were preincubated with a solvent control $(0.1 \%$ DMSO) or CBN $(60$ and $80 \mu \mathrm{M})$ and subsequently treated with collagen $(1 \mu \mathrm{g} / \mathrm{mL})$ for immunoblotting the (a) ERK1/2, (b) JNK1/2, and (c) p38 MAPK phosphorylation. Data are presented as the means $\pm \operatorname{SEM}(n=4) .{ }^{* *} p<0.01$ and ${ }^{* * *} p<0.001$, compared with the resting platelets; ${ }^{\# \#} p<0.01$ and ${ }^{\# \# \#} p<0.001$, compared with the $0.1 \%$ DMSO-treated group

platelets $\left./ 0.01 \mathrm{~mm}^{2}, n=4\right)$. Moreover, the surface coverage of a single platelet treated with CBN was not significantly different compared with $0.1 \%$ DMSO-treated platelets $\left(0.1 \%\right.$ DMSO, $21.5 \pm 4.4 \mu \mathrm{m}^{2} ; 60 \mu \mathrm{M}, 26.1 \pm$ $1.9 \mu \mathrm{m}^{2}$ and $80 \mu \mathrm{M}, 24.2 \pm 1.1 \mu \mathrm{m}^{2}$; $n=4$ ) (Fig. 6c). Furthermore, clot retraction of fibrin polymers, the final step in thrombus formation, is essential for aggregate stabilization and a paradigm of integrin $\alpha_{\mathrm{II}} \beta_{3}$ outsidein signaling [1]. A clot retraction was performed by adding thrombin into a solution containing fibrinogen in the presence of CBN- or 0.1\% DMSO-treated human platelets. As revealed in Fig. 6d, clot retraction was more apparent after 30-min incubation than that after 15 -min incubation in 0.1\% DMSO-treated platelets; however, no substantial decrease was observed in 60 and $80 \mu \mathrm{M}$ CBN-treated platelets, indicating CBN had no significant ability to reduce fibrin clot retraction. Additionally, CBN did not attenuate phosphorylation of proteins, such as integrin $\beta_{3}$, Src, and focal adhesion kinase, in platelets spreading on immobilized fibrinogen. For the purpose to further confirm that CBN did not directly affect integrin $\alpha_{\text {IIb }} \beta_{3}$ binding, we performed a new study by using triflavin, an Arg-Gly-Asp-containing disintegrin purified from Trimeresurus flavoviridis venom, inhibits platelet aggregation through direct interference with fibrinogen binding to integrin $\alpha_{\mathrm{IIb}} \beta_{3}$ [8]. In particular, unlike the binding of fibrinogen or other disintegrins, which requires platelet activation, 

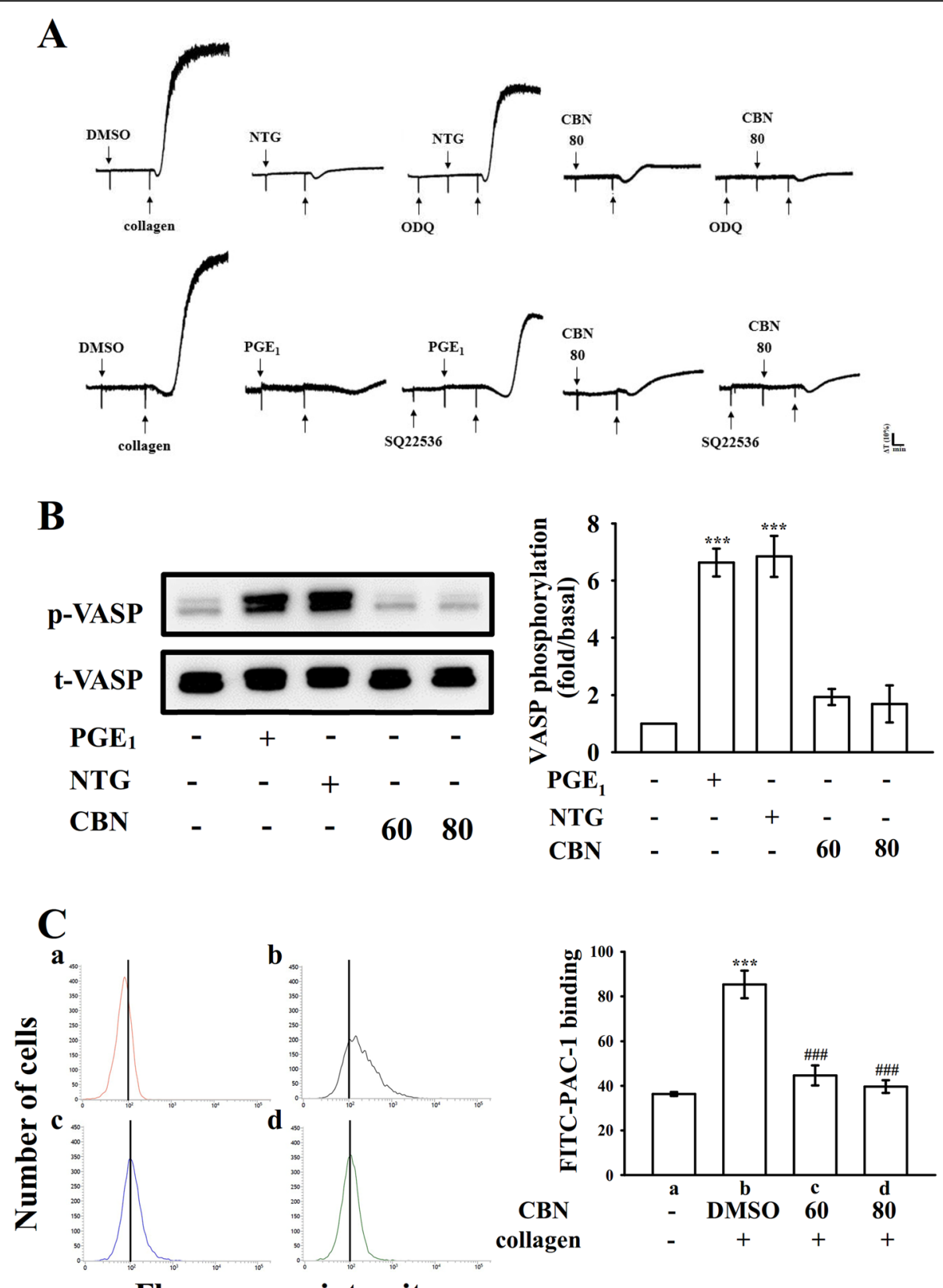

\section{Fluorescence intensity}

Fig. 5 Effect of columbianadin (CBN) in cyclic nucleotides and vasodilator-stimulated phosphoprotein (VASP) phosphorylation as well as integrin $a_{\| 1} \beta_{3}$ activation. Washed platelets $\left(3.6 \times 10^{8}\right.$ cells $\left./ \mathrm{mL}\right)$ were preincubated with (a) prostaglandin $\mathrm{E}_{1}\left(\mathrm{PGE}_{1} ; 1 \mu \mathrm{M}\right)$, nitroglycerin $(\mathrm{NTG} ; 10 \mu \mathrm{M})$, or $\mathrm{CBN}(80 \mu \mathrm{M})$ in the presence of SQ22536 $(100 \mu \mathrm{M})$ or ODQ $(10 \mu \mathrm{M})$ for 3 min before addition of collagen $(1 \mu \mathrm{g} / \mathrm{mL})$ to trigger platelet aggregation. (b) For immunoblotting the VASP phosphorylation, washed platelets were stimulated with PGE $1(1 \mu \mathrm{M})$, NTG $(10 \mu \mathrm{M})$, or CBN (60 and $80 \mu \mathrm{M})$. (c) For flow cytometry analysis, resting platelets ( $a$, red line) or platelets were preincubated with the solvent control (b, 0.1\% DMSO, black line) or CBN (c, $60 \mu \mathrm{M}$, blue line; $d$, $80 \mu \mathrm{M}$, green line) and FITC-conjugated anti-PAC-1 mAb $(2 \mu \mathrm{g} / \mathrm{mL})$ was added before the addition of collagen. Profiles in (a) are representative of four independent experiments. Data are presented as the means $\pm \operatorname{SEM}(n=4) .{ }^{* * *} p<0.001$, compared with the resting group; ${ }^{* \# \#} p<0.001$, compared with the $0.1 \%$ DMSO-treated group

triflavin binds to resting and activated platelets with similar binding affinities (resting, Kd: $76.0 \pm 9.6 \mathrm{nM}$ vs. activated, $\mathrm{Kd}$ : $73.5 \pm 7.4 \mathrm{nM}$ ) and binding numbers [18]. As shown in Fig. 6e, the relative intensity of FITC-triflavin $(2 \mu \mathrm{g} / \mathrm{mL})$ bound to resting platelets was $718.5 \pm 75.5$ ( $a$, black line, $n=4)$, and it significantly decreased in the presence of $2 \mathrm{mM}$ EDTA (negative control, $188.5 \pm 56.5$; $b$, red line, $n=4)$. CBN (60 and $80 \mu \mathrm{M})$ had no effects in reduction of FITC-triflavin binding $(60 \mu \mathrm{M}, 652.3 \pm 89.2$, $c$, blue line; $80 \mu \mathrm{M}, 656.5 \pm 91.1, d$, green line; $n=4$ ) in resting platelets. This result clearly rules out the possibility of CBN directly acts on integrin $\alpha_{\mathrm{IIb}} \beta_{3}$. 


\section{A}
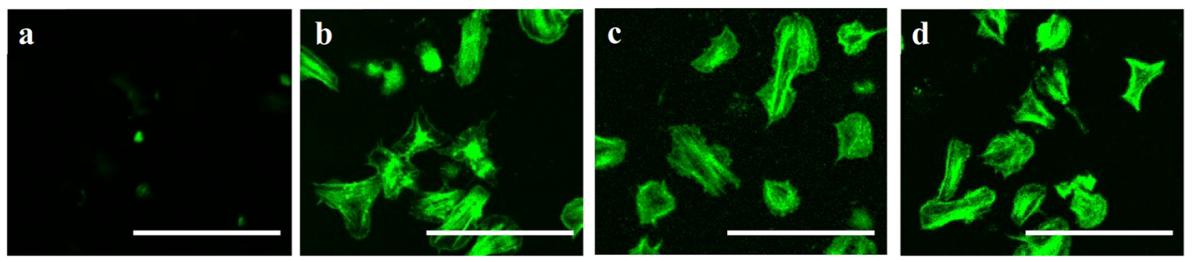

B

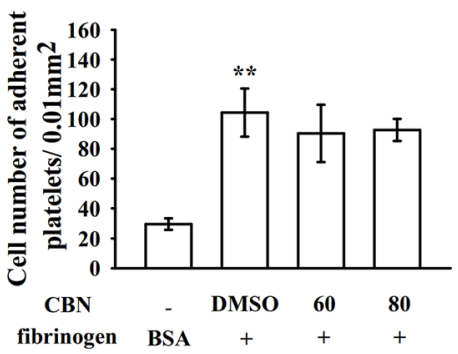

C

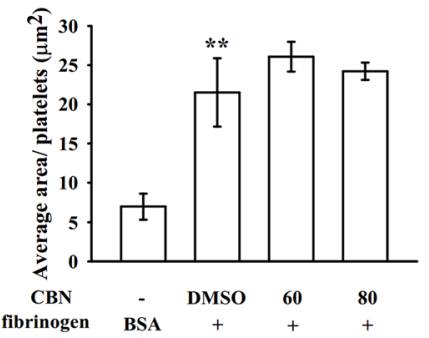

D
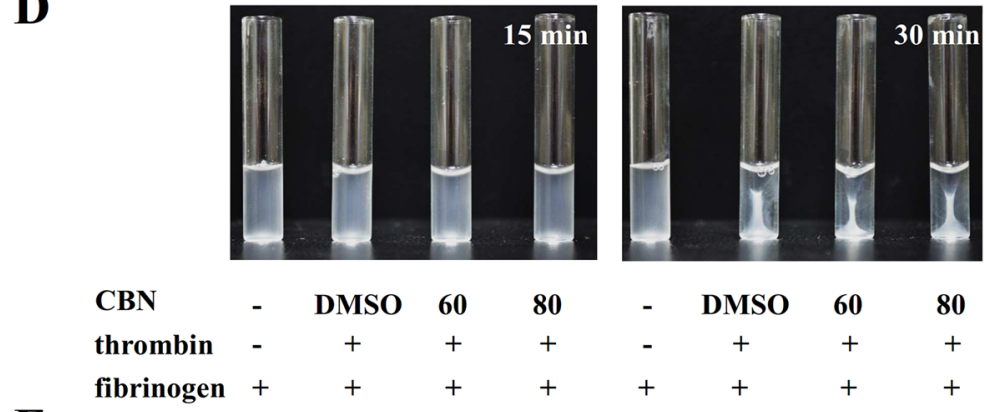

$\mathbf{E}$

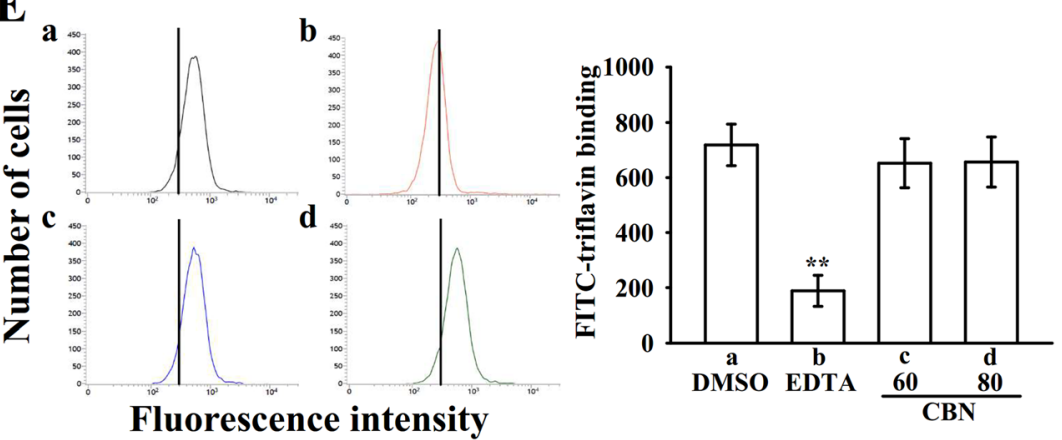

Fig. 6 Effect of columbianadin (CBN) on platelet adhesion, spreading on immobilized fibrinogen and fibrin clot retraction as well as integrin $a_{\| b} \beta_{3}$ binding. (a) Washed platelets allowed to spread on the (a) BSA- or (b- $d$ ) fibrinogen-coated surfaces in the presence of the (b) solvent control $(0.1 \%$ DMSO) or CBN $(c, 60 \mu \mathrm{M} ; d, 80 \mu \mathrm{M})$ and subsequently labeled with FITC-conjugated phalloidin as described in the Materials and methods section. Plot of (b) the number of adherent platelets per $0.01 \mathrm{~mm}^{2}$ and (c) the average spreading surface area of individual platelets in six sight views. (d) Washed platelets suspended in $2 \mathrm{mg} / \mathrm{mL}$ fibrinogen with the solvent control (0.1\% DMSO) or CBN (60 and $80 \mu \mathrm{M})$ before the thrombin $(0.01 \mathrm{U} / \mathrm{mL}$ ) stimulation. Images have been photographed at 15- and 30-min intervals. (e) For flow cytometry analysis, washed platelets were preincubated with solvent control ( $a, 0.1 \%$ DMSO, black line), EDTA ( $b, 2 \mathrm{mM}$, red line), and CBN ( $c, 60 \mu \mathrm{M}$, blue line; $d, 80 \mu \mathrm{M}$, green line), followed by the addition of FITC-triflavin $(2 \mu \mathrm{g} / \mathrm{mL})$. Profiles in $(\mathbf{d})$ are representative of four similar experiments. Data are presented as means \pm SEM $(n=4) .{ }^{* *} p<0.01$, compared with the immobilized BSA group $(\mathbf{b}, \mathbf{c})$ or $0.1 \%$ DMSO-treated group

Regulatory activities of CBN in integrin $a_{1 \mathrm{lb}} \beta_{3}$-mediated protein kinase activation and in vivo vascular thrombus formation

To further elucidate the mechanisms by which CBN impairs integrin $\alpha_{\text {IIb }} \beta_{3}$-mediated outside-in signaling, integrin $\beta_{3}$ phosphorylation, a vital indicator of outside-in signaling, was studied. We examined integrin $\beta_{3}$ phosphorylation in platelets exposed to immobilized fibrinogen through an immunoprecipitation assay and observed that integrin $\beta_{3}$ phosphorylation was not 


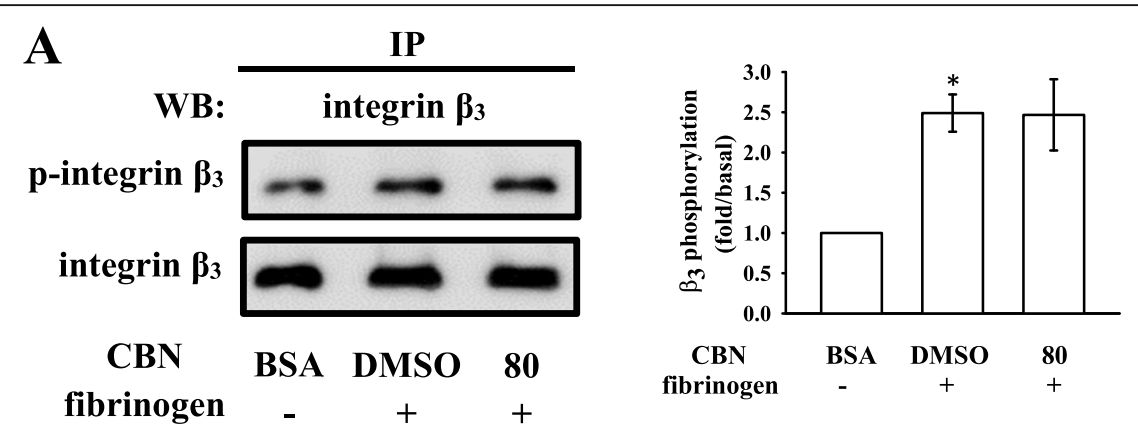

B
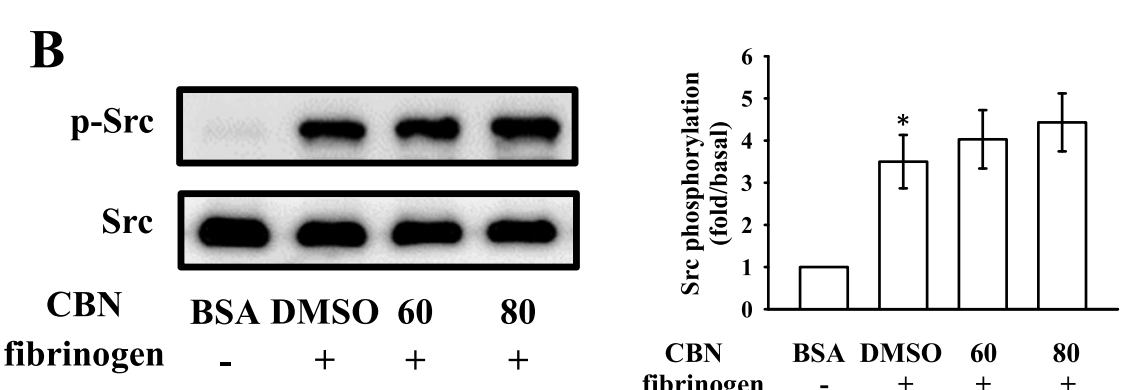

C
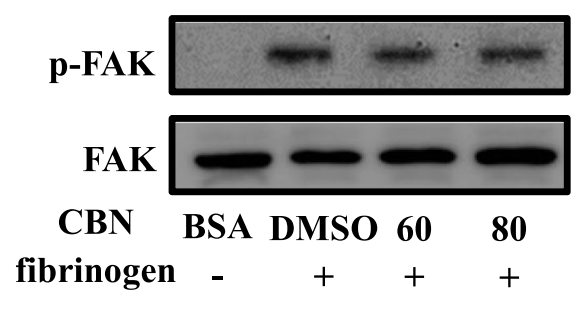

$\begin{array}{ccccc}\text { fibrinogen } & - & + & + & +\end{array}$
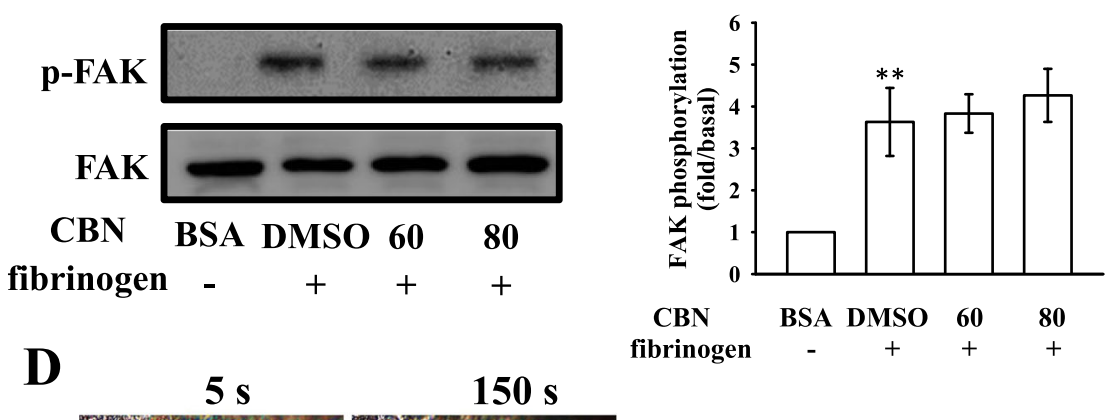

fibrinogen $-\quad+\quad+\quad+$
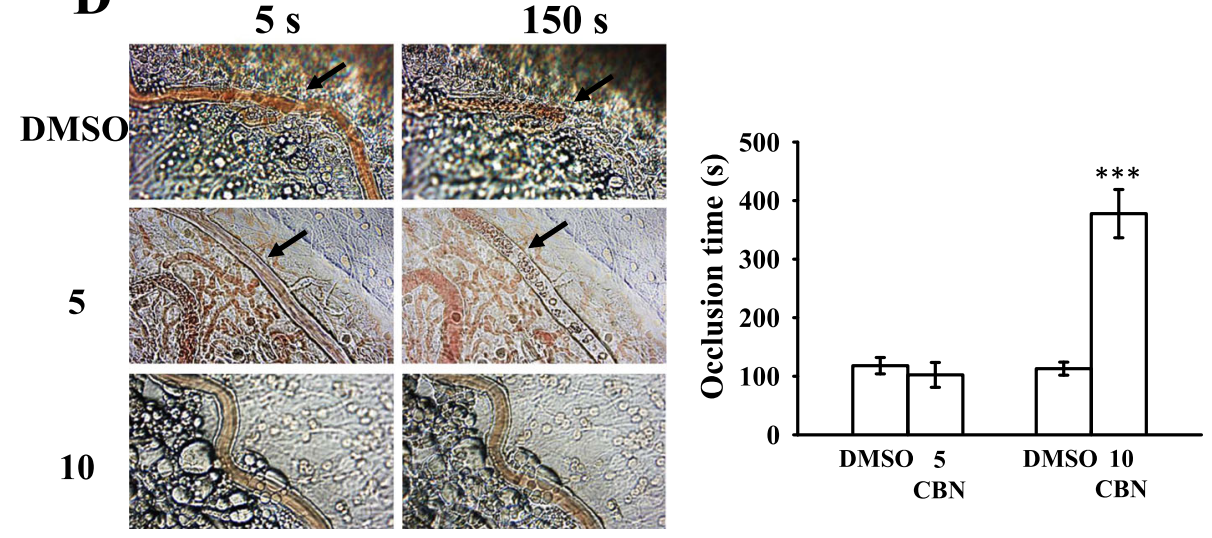

Fig. 7 Effects of columbianadin (CBN) on integrin $\beta_{3}$, Src, and FAK phosphorylation in platelets exposed to a fibrinogen-coated surface and on vascular thrombosis in the mesenteric venules of mice. (a) For immunoprecipitation study, washed platelets were preincubated with the solvent control $(0.1 \%$ DMSO) or CBN $(80 \mu \mathrm{M})$ and allowed to spread on immobilized fibrinogen $(100 \mu \mathrm{g} / \mathrm{mL})$. The platelets were lysed and Protein $\mathrm{G}$ Mag Sepharose Xtra beads were added with the anti-integrin $\beta_{3} \mathrm{mAb}(1 \mu \mathrm{g} / \mathrm{mL})$ for immunoblotting. (b, c) Washed human platelets were preincubated with the solvent control $(0.1 \%$ DMSO) or CBN $(60$ and $80 \mu \mathrm{M})$ and subsequently activated by immobilized fibrinogen $(100 \mu \mathrm{g} / \mathrm{mL})$ for determining the levels of (b) Src and (c) FAK phosphorylation. (d) For animal study, mice were administered an intravenous bolus of the solvent control $(0.1 \% \mathrm{DMSO})$ or CBN $(5$ and $10 \mathrm{mg} / \mathrm{kg})$, and the mesenteric venules were irradiated to induce microthrombus formation (occlusion time). Microscopic images (400x magnification) of $0.1 \%$ DMSO-treated controls and the 5 and $10 \mathrm{mg} / \mathrm{kg}$ CBN-treated groups were recorded at 5 and $150 \mathrm{~s}$ after irradiation, respectively. The photographs are representative of eight similar experiments, and the arrows indicate platelet plug formation. Data are presented as means $\pm \operatorname{SEM}(\mathbf{a}-\mathbf{c}, n=4 ; \mathbf{d}, n=8) .{ }^{*} p<0.05$ and ${ }^{* *} p<0.01$, compared with the immobilized BSA group $(\mathbf{a}-\mathbf{c}) ;{ }^{* * *} p<0.001$, compared with the $0.1 \%$ DMSO-treated group $(\mathbf{d})$ 
significantly attenuated by $\mathrm{CBN}(80 \mu \mathrm{M})$ (Fig. 7a). CBN also had no significant effect on reversing immobilized fibrinogen-induced phosphorylation of Src and FAK (Fig. 7b-c). Overall these data suggested that CBN had no influence on integrin $\alpha_{I I b} \beta_{3}$-mediated outside-in protein kinase phosphorylation.

The antithrombotic activity of CBN was observed in experimental mice. The occlusion time in the mesenteric microvessels of mice pretreated with $15 \mu \mathrm{g} / \mathrm{kg}$ fluorescein sodium was approximately $120 \mathrm{~s}$. The resulting occlusion times were significantly extended after 5 and 10 $\mathrm{mg} / \mathrm{kg}$ CBN treatments compared with those after $0.1 \%$ DMSO treatment (control vs. $5 \mathrm{mg} / \mathrm{kg} \quad \mathrm{CBN}$, $118.0 \pm 14.1 \mathrm{~s}$ vs. $113.1 \pm 11.2 \mathrm{~s}, n=8, p>0.05$; control vs. $10 \mathrm{mg} / \mathrm{kg}$ CBN, $102.3 \pm 21.5 \mathrm{~s}$ vs. $377.7 \pm 41.2 \mathrm{~s}, n=8$, $p<0.001$; Fig. $7 \mathrm{~d}$ ). After irradiation, a thrombotic platelet plug was observed in the mesenteric microvessels at 5 and $150 \mathrm{~s}$, in either $5 \mathrm{mg} / \mathrm{kg} \mathrm{CBN-}$ or $0.1 \%$ DMSOtreated group (Fig. 7d; left panel, arrows). On administration of $10 \mathrm{mg} / \mathrm{kg} \mathrm{CBN}$, platelet plug formation was only observed at $5 \mathrm{~s}$, but not at $150 \mathrm{~s}$ after irradiation (Fig. 7d). Furthermore, we also investigated and compared the therapeutic effects of CBN with aspirin in preventing acute pulmonary embolism death in mice as shown in Table 1. The results indicated that treatment with $\mathrm{CBN}$ at 5 and $10 \mathrm{mg} / \mathrm{kg}$ significantly lowered the ADP $(0.7 \mathrm{mg} / \mathrm{g})$-induced mortality rate in mice from $100 \%$ ( 8 dead, $n=8)$ to $50 \%$ ( 4 dead, $n=8)$, and $0 \%(0$ dead, $n=8)$, respectively. In addition, aspirin $(20 \mathrm{mg} / \mathrm{kg})$ also reduced the mortality to $25 \%$ ( 6 dead, $n=8$ ) in this experiment (Table 1).

\section{Discussion}

This study reveals that in addition to the well-known properties of $\mathrm{CBN}$, it also possesses antiplatelet activity in humans. It can be satisfactorily absorbed from gastrointestinal tract into bloodstream and distributed into organs [19]. Thus, the intake of CBN or natural of nontoxic prophylactic agents, such as food products and nutritional supplements, is ideal to prevent atherothrombotic events.

In the current study, CBN more potently inhibited collagen-induced platelet aggregation, but only slightly (not

Table 1 Effect of columbianadin (CBN) and aspirin on mortality of acute pulmonary thrombosis caused by intravenous injection of ADP in experimental mice

$\begin{array}{ll}\text { Total } & \begin{array}{l}\text { Number of } \\ \text { number }\end{array} \\ \text { deaths }\end{array}$

\begin{tabular}{llll}
\hline ADP $(0.7 \mathrm{mg} / \mathrm{g})$ & & & \\
+ solvent control $(0.1 \%$ DMSO $)$ & 8 & 8 & 100 \\
+ CBN $(5 \mathrm{mg} / \mathrm{kg})$ & 8 & 4 & 50 \\
+ CBN $(10 \mathrm{mg} / \mathrm{kg})$ & 8 & 0 & 0 \\
+ aspirin $(20 \mathrm{mg} / \mathrm{kg})$ & 8 & 2 & 25 \\
\hline
\end{tabular}

statistically significant) inhibited other platelet agonists; this implied that CBN was effective in inhibiting platelet aggregation through a prominent PLC-dependent mechanism. The platelet stimulation by agonists, for example collagen, noticeably modified phospholipase activation. The PLC activation resulted in $\mathrm{IP}_{3}$ and DAG formation, which activated $\mathrm{PKC}$, inducing $\mathrm{p} 47$ protein phosphorylation [20]. PLC enzyme is composed of several subtypes in which PLCY family can be further divided into two isozymes, namely PLC $\gamma 1$ and PLC $\gamma 2$. PLC 22 participates in collagendependent signaling in platelets [21]. In our present study, CBN reduced the collagen-activated PLC 2 / PKC phosphorylation but without inhibition of PDBuinduced platelet aggregation; this suggested that CBN had no direct effects on PKC. Akt (downstream regulator of PI3K)-knockout mice have defective platelet activation [22]. Hence, Akt activation may be an attractive target for the development of antithrombotic therapeutics. Although effectors through which Akt contributes to platelet activation are not definitively known, several candidates have been discussed, including glycogen synthase kinase $3 \beta$, phosphodiesterase $3 \mathrm{~A}$, and the integrin $\beta_{3}$ [22]. Additionally, it has been observed that both PI3K/Akt and MAPKs are mutually activated and PKC is the upstream regulator in platelets [23].

MAPKs constitute a family of serine/threonine kinases that convert extracellular stimuli into cellular responses. Conventional MAPKs can be divided into the ERK1/2, p38 MAPK $(\alpha, \beta, \gamma$, and $\delta)$, JNK1/2, and big MAPK (ERK5) [24]. The ERK1/2, JNK1/2, and p38 MAPK have been found to participate in platelet activation [24]. All of these kinases are activated by specific MAPK kinases (MEKs). The intracellular roles of JNK1/2 and ERK1/2 in platelets remain unclear, but evidence shows that the suppression of integrin $\alpha_{\mathrm{II}} \beta_{3}$ activation may be involved [25]. Moreover, ERK activation is essential for collageninduced platelet aggregation [26]. Cytosolic phospholipase $\mathrm{A}_{2}\left(\mathrm{CPLA}_{2}\right)$, which catalyzes AA release to produce thromboxane $\mathrm{A}_{2}$, which is an important substrate of $\mathrm{p} 38$ MAPK activation induced by various platelet agonists such as thrombin [27]. The present study revealed that CBN-mediated inhibition of collagen-stimulated platelet activation involved ERK1/2 and JNK1/2 activation, but not p38 MAPK activation, which may explain why CBN presents higher effectiveness for collagen stimulation than that for AA, U46619, and thrombin. Moreover, Fan et al. [24] reported that ERK1/2 and JNK1/2, but not p38 MAPK, are the major mitogen-activated protein 3 kinase (MEKK3) downstream signaling molecules in platelet activation. Therefore, we speculated that CBN may act on the MEKK3, resulting in inhibition of ERK1/ 2 and JNK1/2 phosphorylation. However, further studies are required for clarification. 
Elevation of cyclic nucleotides, such as cyclic AMP and cyclic GMP, in platelets activates their respective protein kinase A and protein kinase G. This modulates platelet activation by phosphorylating intracellular protein substrates, such as VASP, which are involved in the inhibition of platelet aggregation and platelet adhesion [28]. Increased levels of cyclic nucleotides prevent most of the platelet responses and decrease the intracellular $\left[\mathrm{Ca}^{2+}\right] \mathrm{i}$ through $\mathrm{Ca}^{2+}$ uptake into the dense tubular system, which suppresses the activation of PLC/PKC signaling. In this study, neither SQ22536 nor ODQ significantly reversed the CBN-mediated inhibitory response, and CBN had no effects on VASP phosphorylation. Therefore, the CBNmediated inhibition of platelet activation is independent of the intracellular cyclic nucleotides/VASP pathway.

The fibrinogen-integrin $\alpha_{\mathrm{II}} \beta_{3}$ binding belongs to a major component of activated platelets. Integrin $\alpha_{\mathrm{IIb}} \beta_{3}$ undergoes conformational changes upon activation, generating a unique and specific ligand-binding site for the fibrinogen, von Willebrand factor, and fibronectin [1]. Platelet adheres to immobilized fibrinogen and mediates clot retraction; these processes are involved in integrin $\alpha_{\text {IIb }} \beta_{3}$ outside-in signaling [1]. PAC-1 reacts with the activation-induced conformational epitope of integrin $\alpha_{\mathrm{IIb}} \beta_{3}$ [29], and the PAC-1 binding was observed to be markedly reduced by $\mathrm{CBN}$ treatment. In addition, platelet-mediated fibrin clot retraction is also mediated by integrin $\alpha_{\mathrm{II}} \beta_{3}$. Integrin $\alpha_{\mathrm{II}} \beta_{3}$-mediated signaling begins immediately after a fibrinogen molecule binds to the integrin; this outside-in signaling results in tyrosine phosphorylation of numerous proteins, such as the Src family kinases (SFK; e.g., Src, Lyn, and Fyn), FAK, and the cytoplasmic tail of integrin $\beta_{3}$ at Tyr759, a process dependent on outside-in signaling and cytoskeleton reorganization [1]. The critical role of integrin $\beta_{3}$ at Tyr759 in platelets was demonstrated in vivo, and its mutation led to bleeding disorder and strongly affected clot retraction responses in vitro [30]. FAK, a cytoplasmic tyrosine kinase located at focal adhesion points, plays a vital role in cytoskeleton regulation and integrin $\alpha_{\mathrm{IIb}} \beta_{3}$ activity [31]. Platelet adhesion to immobilized fibrinogen requires FAK activation through integrin $\alpha_{\mathrm{II}} \beta_{3}$, and in turn activation of FAK requires autophosphorylation [31]. In this study, CBN had no effects on platelet adhesion and spreading and fibrin clot retraction, as well as phosphorylation of integrin $\beta_{3}$, Src, and FAK on immobilized fibrinogen, indicating that CBN influences integrin $\alpha_{\mathrm{II}} \beta_{3}$ inside-out but not outside-in signaling.

After vascular endothelial cell injury, exposure to subendothelial collagen is the major trigger that initiates platelet adhesion and aggregation at the injury site, followed by vascular thrombosis. Animal models of vascular thrombosis are necessary in order to understand the effectiveness of test compounds for this disease. An ideal mouse model should be technically simple, quick in operation, and easily reproducible. In a vascular thrombotic mice model [11], mesenteric venules were continuously irradiated by fluorescein sodium throughout the experimental period, leading to strong damage to the endothelium, treatment with $10 \mathrm{mg} / \mathrm{kg}$ CBN significantly extended the occlusion times; in studies on acute pulmonary thromboembolism, platelet aggregation is intimately involved in experimental thrombosis, and CBN effectively prevented ADP-induced thromboembolic death. We also found that $\mathrm{CBN}$ is more effectiveness than aspirin at lowering mortality in acute pulmonary thromboembolism. These data are consistent with the fact that platelet aggregation is a more crucial factor causing vascular thrombosis. Therefore, CBN may represent a potential natural compound for treating thromboembolic disorders.

\section{Conclusion}

This study revealed a novel role of CBN in the inhibition of platelet activation in humans, suggesting that it can be used for potential therapeutic or prophylactic applications. The outcome of this study may provide a new insight into the role of $\mathrm{CBN}$ in human platelet activation because it significantly inhibited platelet activation by hindering the PLCY2-PKC cascade and subsequently, suppressed the activation of Akt and ERKs/JNKs. These changes decrease the release, such as $\left[\mathrm{Ca}^{2+}\right] \mathrm{i}$, followed by integrin $\alpha_{\mathrm{II}} \beta_{3}$ inside-out signaling and inhibition of platelet aggregation.

\section{Abbreviations \\ AA: Arachidonic acid; ADP: Adenosine diphosphate; ATP: Adenosine triphosphate; BSA: Bovine serum albumin; CBN: Columbianadin; CVDs: Cardiovascular diseases; DAG: Diacylglycerol; DMSO: Dimethyl sulfoxide; ERK: Extracellular signal-regulated kinase; FAK: Focal adhesion kinase; $I_{3}$ : Inositol trisphosphate; JNK: c-Jun N-terminal kinase; LDH: Lactate dehydrogenase; LPS: Lipopolysaccharide; MAPK: Mitogen-activated protein kinase; NO: Nitric oxide; NTG: Nitroglycerin; PDBu: Phorbol-12,13-dibutyrate; $\mathrm{PGE}_{1}$ : Prostaglandin $\mathrm{E}_{1} ;$ PKC: Protein kinase C; PLC 2 2: Phospholipase CY2; VASP: Vasodilator-stimulated phosphoprotein}

\section{Acknowledgements \\ Not applicable.}

\section{Authors' contributions}

SMH and JRS participated in research design. SMH, CWH, and CLT carried out most of the experiments, including platelet aggregation, immunoblotting, and the animal study. CHH performed platelet function analysis. TJ and JRS wrote the manuscript. TJ and MV performed data analyses. All authors provided clarification and guidance on the manuscript. All authors were involved in editing the manuscript and approved the final manuscript.

\section{Funding}

This work was supported by grants from the Ministry of Science and Technology of Taiwan (MOST 107-2320-B-038-035-MY2 and MOST108-2320B-038-031-MY3), Taipei Medical University (DP2-107-21121-N-02), and Cathay General Hospital (CGH-MR-A10715 and CGH-MR-A108017).

Availability of data and materials

All data generated or analyzed during this study are included in this published article. 


\section{Ethics approval and consent to participate}

This study was approved by the Institutional Review Board of Taipei Medical University (TMU-N201612050) and conformed to the directives of the Declaration of Helsinki. All animal experiments and care procedures conformed to the Guide for the Care and Use of Laboratory Animals (LAC-2016-0276) and were approved by the Institutional Animal Care and Use Committee of Taipei Medical University.

\section{Consent for publication}

Not applicable.

\section{Competing interests}

The authors declare no conflict of interests.

\section{Author details}

'Department of Cardiovascular Center, Cathay General Hospital, No. 280 Renai Rd. Sec.4, Taipei 106, Taiwan. ${ }^{2}$ Division of Cardiovascular Surgery, Department of Surgery, School of Medicine, College of Medicine, Fu Jen Catholic University, No.510, Zhongzheng Rd, New Taipei City 242, Taiwan. ${ }^{3}$ Graduate Institute of Medical Sciences, College of Medicine, Taipei Medical University, 250 Wu-Hsing Street, Taipei 110, Taiwan. ${ }^{4}$ Graduate Institute of Metabolism and Obesity Sciences, Collage of Nutrition, Taipei Medical University, No. 250, Wu Hsing St, Taipei 110, Taiwan. ${ }^{5}$ Translational Medicine Center, Shin Kong Wu Ho-Su Memorial Hospital, No. 95, Wenchang Rd, Taipei 111, Taiwan. ${ }^{6}$ Department of Chemistry, North Eastern Hill University, Shillong 793022, India.

Received: 9 September 2019 Accepted: 14 January 2020

Published online: 06 May 2020

\section{References}

1. Payrastre B, Missy K, Trumel C, Bodin S, Plantavid M, Chap H. The integrin alpha Ilb/beta 3 in human platelet signal transduction. Biochem Pharmacol. 2000;60(8):1069-74.

2. Kang JI, Hong JY, Choi JS, Lee SK. Columbianadin inhibits cell proliferation by inducing apoptosis and necroptosis in HCT116 colon cancer cells. Biomol Ther. 2016;24(3):320-7.

3. Zhang C, Hsu AC, Pan H, Gu Y, Zuo X, Dong B, et al. Columbianadin suppresses lipopolysaccharide (LPS)-induced inflammation and apoptosis through the NOD1 pathway. Mol. 2019. https://doi.org/10.3390/ molecules24030549.

4. Lim HJ, Lee JH, Choi JS, Lee SK, Kim YS, Kim HP. Inhibition of airway inflammation by the roots of Angelica decursiva and its constituent, columbianadin. J Ethnopharmacol. 2014;155(2):1353-61.

5. Li RZ, He YQ, Chiao M, Xu Y, Zhang QB, Meng JR, et al. Studies of the active constituents of the Chinese drug "Duhuo" Angelica pubescens. Acta Pharm Sin. 1989:24(7):546-51.

6. Chen WF, Lee JJ, Chang CC, Lin KH, Wang SH, Sheu JR. Platelet proteaseactivated receptor (PAR)4, but not PAR1, associated with neutral sphingomyelinase responsible for thrombin-stimulated ceramide-NF-kB signaling in human platelets. Haematol. 2013;98(5):793-801.

7. Sheu JR, Lee CR, Lin CH, Hsiao G, Ko WC, Chen YC, et al. Mechanisms involved in the antiplatelet activity of Staphylococcus aureus lipoteichoic acid in human platelets. Thromb Haemost. 2000:83(5):777-84.

8. Sheu JR, Hung WC, Wu CH, Ma MC, Kan YC, Lin CH, et al. Reduction in lipopolysaccharide-induced thrombocytopenia by triflavin in a rat model of septicemia. Circ. 1999;99(23):3056-62.

9. Hsia CH, Lu WJ, Lin KH, Chou DS, Geraldine P, Jayakuma T, et al. NCTD, a clinical used chemotherapeutic agent, acts as a powerful inhibitor by interfering with fibrinogen-integrin $\alpha_{\| b} \beta_{3}$ binding in human platelets. J Cell Mol Med. 2018;22(4):2142-52

10. Osdoit S, Rosa JP. Fibrin clot retraction by human platelets correlates with alpha (Ilb)beta(3) integrin-dependent protein tyrosine dephosphorylation. J Biol Chem. 2001;276(9):6703-10.

11. Hsiao G, Lin KH, Chang Y, Chen TL, Tzu NH, Chou DS, et al. Protective mechanisms of inosine in platelet activation and cerebral ischemic damage. Arterioscler Thromb Vasc Biol. 2005:25(9):1998-2004.

12. Sheu JR, Hung WC, Wu CH, Lee YM, Yen MH. Antithrombotic effect of rutaecarpine, an alkaloid isolated from Evodia rutaecarpa, on platelet plug formation in in vivo experiments. Br J Haematol. 2000;110(1):110-5.
13. Cosemans JM, Iserbyt BF, Deckmyn H, Heemskerk JW. Multiple ways to switch platelet integrins on and off. J Thromb Haemost. 2008;6(8):1253-61.

14. Varga-Szabo D, Braun A, Nieswandt B. Calcium signaling in platelets. J Thromb Haemost. 2009;7(7):1057-66.

15. Manning BD, Cantley LC. AKT/PKB signaling: navigating downstream. Cell. 2007;129(7):1261-74

16. Cargnello M, Roux PP. Activation and function of the MAPKs and their substrates, the MAPK-activated protein kinases. Microbiol Mol Biol Rev. 2011; 75(1):50-83.

17. Shattil SJ. The beta3 integrin cytoplasmic tail: protein scaffold and control freak. J Thromb Haemost. 2009;7(1):210-3.

18. Huang TF, Sheu JR, Teng CM, Chen SW, Liu CS. Triflavin, an antiplatelet ArgGly-asp-containing peptide, is a specific antagonist of platelet membrane glycoprotein IIb-IIla complex. J Biochem. 1991;109(2):328-34.

19. Zhang YB, Li W, Yang XW. Biotransformation of columbianadin by rat hepatic microsomes and inhibition of biotransformation products on $\mathrm{NO}$ production in RAW 264.7 cells in vitro. Phytochemistry. 2012;81:109-16.

20. Liu Y, Liu T, Ding K, Liu Z, Li Y, Te H, et al. Phospholipase CY2 signaling cascade contribute to the antiplatelet effect of notoginsenoside Fc. Front Pharmacol. 2018. https://doi.org/10.3389/fphar.2018.01293.

21. Ragab A, Severin S, Gratacap MP, Aguado E, Malissen M, Jandrot-Perrus M, et al. Roles of the C-terminal tyrosine residues of LAT in GPVI-induced platelet activation: insights into the mechanism of PLC gamma 2 activation. Blood. 2007;110(7):2466-74.

22. Woulfe DS. Akt signaling in platelets and thrombosis. Expert Rev Hematol. 2010;3(1):81-91.

23. Jayakumara T, Chen WF, Lu WJ, Chou DS, Hsiao G, Hsu CY, et al. A novel antithrombotic effect of sulforaphane via activation of platelet adenylate cyclase: ex vivo and in vivo studies. J Nutr Biochem. 2013;24(6):1086-95.

24. Fan X, Wang C, Shi P, Gao W, Gu J, Geng Y, et al. Platelet MEKK3 regulates arterial thrombosis and myocardial infarct expansion in mice. Blood Adv. 2018;2(12):1439-48.

25. Hughes PE, Renshaw MW, Pfaff M, Forsyth J, Keivens VM, Schwartz MA, et al. Suppression of integrin activation: a novel function of a Ras/Raf-initiated MAP kinase pathway. Cell. 1997;88(4):521-30.

26. Adam F, Kauskot A, Rosa JP, Bryckaert M. Mitogen-activated protein kinases in hemostasis and thrombosis. J Thromb Haemost. 2008:6(12):2007-16.

27. Coulon L, Calzada C, Moulin P, Vericel E, Lagarde M. Activation of p38 mitogen-activated protein kinase/cytosolic phospholipase $A_{2}$ cascade in hydroperoxide-stressed platelets. Free Radic Biol Med. 2003;35(6):616-25.

28. Benz PM, Laban H, Günther L, Gambaryan S, Dib K. Vasodilator-Stimulated Phosphoprotein (VASP)-dependent and -independent pathways regulate thrombin-induced activation of Rap1b in platelets. Cell Commun Signal. 2016; doi:org/https://doi.org/10.1186/s12964-016-0144-z.

29. Shattil SJ, Cunningham M, Hoxie JA. Detection of activated platelets in whole blood using activation-dependent monoclonal antibodies and flow cytometry. Blood. 1987;70(1):307-15.

30. Law DA, DeGuzman FR, Heiser P, Ministri-Madrid K, Killeen N, Phillips DR. Integrin cytoplasmic tyrosine motif is required for outside-in alphallbbeta3signaling and platelet function. Nat. 1999:401(6755):808-11.

31. Schaller MD. Cellular functions of FAK kinases: insight into molecular mechanisms and novel functions. J Cell Sci. 2010;123(pt 7):1007-13.

\section{Publisher's Note}

Springer Nature remains neutral with regard to jurisdictional claims in published maps and institutional affiliations.

Ready to submit your research? Choose BMC and benefit from:

- fast, convenient online submission

- thorough peer review by experienced researchers in your field

- rapid publication on acceptance

- support for research data, including large and complex data types

- gold Open Access which fosters wider collaboration and increased citations

- maximum visibility for your research: over $100 \mathrm{M}$ website views per year

At $\mathrm{BMC}$, research is always in progress.

Learn more biomedcentral.com/submissions 